\title{
Investigating EFL Prospective Teachers' Ability to Translate idioms
}

Heba Abdelsabour Abdelazim

MA Candidate, October 6 University

Abstract

The main objective of this study is to investigate
EFL teachers' ability to translate idioms and to
measure their translation strategy awareness. The study tried to answer two questions: To what extent are EFL teachers at October 6 university able to translate idioms and to what extent are EFL prospective teachers at October 6 university aware of translation strategies? The study sample is English majors at the Faculty of Education, October 6 University. Some of the EFL upcoming teachers participated in the study as they were carrying out their final exams of the second term of the academic year 2018-2019. The study involved 43 EFL prospective teachers. The study sample involved only fourth year English language majors that should be highly aware of the courses of English and translation. To collect the required data, a translation test and translation strategy awareness questionnaire were made, validated and administered. The administration of the study instruments happened in their final second term of the academic year 2018-2019. The sample of the present study were asked to translate 20 items in addition to respond to translation strategy awareness questionnaire through ticking the strategies they use in translation. Results manifest that $86.05 \%$ of the study sample were unable to pass a translation test and their awareness regarding translation strategies was poor since they got $40.42 \%$ whereas the cut-off level was 50\%. Finally, some suggestions and recommendations were proposed.

Key words : EFL Prospective Teachers - Ability to Translate idioms

\section{Introduction}

Studying language, culture and translation and the relationship between them are valuable issues due to the importance of human communication in the world. 
The variety of languages with different cultures and necessity of communications in human life caused translation to be a very effective factor in communicating and exchanging cultures, and knowledge. Thus, it seems that language and culture are closely related and it is essential to consider both in the process of translation. Although it is difficult to find a specific frame or definite rules on how a translation must be done, many translators who transfer natural meaning based on the cultural and religious norms of their society, encounter some limitations and censorship through translation. Hence, culture and cultural expressions have a great role in translation. Moreover, Translation has an important role in globalization of cultures especially pop culture leading to expanding ethnic habits and customs, or religious values. As languages and culture are complimentary of each other, and cultural features of every region is different, translators not only should concentrate on how to convey the same meaning, but also attempt to show the dissimilarities between two cultural perspectives.(International Conference on Language, Medias and Culture,2012)

\section{Statement of Problem}

Although idioms are very important and they are one of cultural-bound expressions, they consider one of the most difficulties in translation that EFL prospective teachers face at October 6 University. Hence, this study investigating EFL prospective teachers' ability to translate idioms in addition to identify the most common translation strategies they use in idiom translation. 


\section{Study Questions}

- To what extent are EFL teachers at October 6 University able to translate idioms?

- To what extent are EFL prospective teachers at October 6 University aware of translation strategies?

\section{Hypotheses of the Study}

The study attempted to test the following two hypotheses:

- EFL prospective teachers in October 6 University show weak performance in translating idioms on the translation test.

- EFL prospective teachers show weak translation strategy awareness questionnaire.

\section{Aims of the Study}

The study attempted to achieve the following objectives:

- To investigate EFL prospective teachers' ability to translate idioms.

- To identify the most common strategies used by prospective teachers in October 6 University in translating idioms.

- To develop idiomatic competence translation test (ICTT).

- To develop translation strategy awareness questionnaire (TASQ).

\section{Significance of the Study}

The significance of this study is derived from the following:

- The study in hand may be one of the leading studies which put the question of translating idioms within EFL disciplines. 
- This study may be considered a useful study of which tackled the connection between translation and cultural idioms.

- The outcomes of the study may be helpful in account of improving teaching of translation in some Education faculties.

\section{7. Delimitations of the Study}

The study abided by the following delimitations:

- A sample of 4th year English Majors at the Faculty of Education, October 6 University.

- Investigating EFL Prospective Teachers' Ability to Translate idiom at the Faculty of Education, October 6 University.

\section{Methodology}

\section{Participants:}

This study is directed at the English majors of English at faculty of education, October 6 University. Some of the EFL upcoming teachers participated in the study as they were carrying out their final exams of the second term of the academic year 2018-2019. The study involved $43 \mathrm{EFL}$ prospective teachers years. The study sample involved only fourth year English language Majors that should be highly aware of the courses of English and translation.

\section{Instruments}

\section{1-Idiomatic competence Translation Test (ICTT):}

The ICTT aimed greatly at promoting the ability of EFL prospective teachers to interpret idioms in order to provide the data necessary for giving an answer to question of the first study. Meanwhile, the researcher investigated the pertinent literature and former studies to identify the most frequent cultural idioms with 
regard to American culture. On the other hand, the initial list of such idioms was revised by three EFL specialists from the University of October 6 . Some items of the list were deleted whereas other items were modified. Following the modifications and correction of the items, the twenty items of the list were considered valid content of the ICTT. The second step was to determine the design of the test. Each test item within the test contains one cultural idioms with the aim of giving the test-takers the opportunity to answer the test tasks easily. Since they were demanded to translate each item into entire meaningful Arabic statement. The test included twenty statements concerning both idioms.

In order to evaluate the validity and reliability of ICTT, the same EFL specialists revised the test and confirmed its validity and authenticity. To add, the test was conducted twice for the purpose of assessing the reliability of ICTT. It was conducted on the 8th of April 2019 to 9 University English language majors at October 6. Furthermore, it was re-conducted after a week on the same students. The researcher employed the test-retest procedure in order to calculate the ICTT reliability through the application of Pearson productmoment correlation coefficient. The reliability coefficient of the ICTT was ( $\mathrm{r}=0.81)$.

Regarding the administration of the test, the ICTT was conducted on Thursday the 28th April 2019 at the October6 University within the second semester of the academic year 2018-2019. Students were given the test addition to systematized formal test papers. The test administrator asked the students not to begin their answer of translation if they do not finish their formal test. They were initially informed that the translation 
test is not basic on account for their academic scores or performance, however it was considered as a part of their academic study. In the aftermath of the test, answers of the students were gathered. The duration of the test was an hour. On the other hand, the overall score of the ICTT was 40 scores as each item among the twenty-six items was dedicated two points. Two points were devoted to accurate cultural translation, whereas one point was dedicated to any adequate translation. Students who gave literal or unacceptable translation scored zero. Scores of the students were evaluated with respect to five factors; less than $60 \%$ means poor, from $60 \%$ to $69 \%$ means fair ,whereas from $70 \%$ to $79 \%$ means good. From $80 \%$ to $89 \%$ means very good, and from $90 \%$ to $100 \%$ means excellent. The answers and performance of the participants were scored by three EFL specialists (PhD holders).

\section{2-Translation Strategy Awareness Questionnaire (TSAQ)}

The TSAQ aimed basically at identification of the translation strategies employed by EFL teachers in case of translation of cultural idioms with the aim of providing the exact data necessary for the response of the second study question which is: To what extent are EFL prospective teachers aware of translation strategy?

There are 15 translation strategies involved in the questionnaire. These are: addition, combination, compensation, translation by paraphrase, cultural equivalent translation, idiomatic translation, descriptive translation, function translation, adaptation, modulation, structure-shift, transposition, coherence change, speech act and translation by omission. Administrators meanwhile asked the participants to 
manifest the frequency of the strategies which they employed within translating the item of the ICTT test. With respect to the validity as well as reliability of the TSAQ, three EFL specialists revised the questionnaire times and announced its validity on account for its form and content. Furthermore, the questionnaire was conducted twice for the purpose of assessing the reliability of the TSAQ to 3 University English Majors at October 6 University. The researcher on the other hand, employed the test-retest procedure with the aim of estimating the reliability of the TSAQ. The TSAQ coefficient was $(r=0,82)$. Participants were given the questionnaire within the sessions of their formal examination of the second semester of the academic year 2018-2019. Meanwhile the participants' regularity of answers to the items of the questionnaire were estimated with regard to the criteria that: Value of Total Response $=$ Frequency of strategy (n) multiply by Value of Response where (Always $=5$, usually $=4$, sometimes $=3$, rarely $=2$, as well as never $=1$ ).

\section{2- Review Of Literature}

\section{2-1Idioms and Translation Challenges}

Idioms are phrases in which the meaning of the whole idiom cannot be concluded from the meaning of its parts. For example, kick the bucket, break a leg, etc. They are fixed prior prepared chunks of words which have the same function of single lexical items. Specifically, they are "bits of frozen syntax, whose meaning cannot be derived from the meaning of their constituents...more than simply the sum of their individual parts"(Nattinger and De Carrico 1992:33). There are two principles that organize language: open choice and idioms. The previous are elements that can be employed with diverse words with no big difference. 
On the other hand, the latter are combinations of words that give different meanings together. He shed light on idioms as the default mode in enhancing our language. Most normal texts is largely delexicalized, and appears to be formed by exercise of the idiom principle

The translation student faces difficulties in dealing with idioms such as; understanding the idiom in the SL, and finding an equivalent in the TL, that because, the fact that English, in contrast to Arabic, is the most idiomatic language.

\subsection{Types of Idioms}

Idioms differ according to how transparent their meaning is. They may be categorized into many types. Shojaei (2012) mentioned Fernando classification of idioms, he classified them into three categories: pure, semi-literal and literal idioms. Pure idioms are "conventionalized", non-literal expressions, such as; (smell a rat), while semi-literal idioms involve at least one word that carries its literal meaning, like drop names. According to Fernando phrases or expressions, such as dark and handsome and (Merry Christmas) and a (happy New Year), are literal idioms. Fernando's lexicogrammatical categorization divides pure, semiliteral and literal idioms into twelve classes according to their variability and figurativeness. However, since there are multiple categories and they overlap with each other. In addition to these kinds of categorization, Fernando classifies idioms by their structure or form. Idioms may be categorized as idioms of invariance and those of restricted variance according to their degree of fixedness in form.

Poshi and Lacka (2016) mentioned that Moon has divided idioms, into three classes: anomalous collocations, formulae and metaphors, each of which 
consist of various subcategories. Anomalous collocations are strings classified in lexicogrammatical terms, formulae are specialized pragmatically and metaphors relate to semantics. Moon has divided metaphors into the following subcategories: transparent metaphors, semi-transparent metaphors and opaque metaphors. They are all non-compositional but they differ in degrees of transparency.

When the literal meaning creates an image in mind of the hearer or reader, the reader can easily discover the figurative meaning (e.g. pack one's bags), they consist of meanings which can simply recover from its parts. Geeraert (2016) mentioned that Knowledge of the Idiom is a significant predictor - the idiom is rated as more transparent, or obvious in meaning, when it is known. This predictor also occurs in several significant interactions, such as with the Frequency of the Idiom. When participants do not know an idiom, they are not affected by its frequency, as expected. But if they know the idiom, they rate more frequent idioms as more transparent. Knowledge of the Idiom also occurs in a significant interaction with Like Using Idioms. Participants who do not know an idiom rate this unknown expression as more transparent if they enjoy using idioms. It is inferred that a variety of factors, not just the compositionality of the phrase, contribute to the transparency of an idiom. They also reveal the importance of analyzability - the speaker's ability to make sense of the idiom. Moreover, individual differences, such as one's experience with or enjoyment of using idioms, can also have influential effects on how transparent speakers consider an idiom.

While semi-transparent idioms are expressions where the link between the literal meaning and the 
figurative meaning is not as clear as with fully transparent idioms. Furthermore, in order to be able to understand a semi-transparent idiom (e.g. grasp the nettle) specialist knowledge is required. Opaque idioms are idioms where comprehension and interpretation of the image is impossible without knowing the etymology (e.g. red herring). This classification will be useful when examining the degree of transparency of idioms. Moon's division is adequate since it is important to recognize and discern various stages of metaphoricity but it is not justifiable to try to make more than three categories because they overlap and the borders between them can be blurred. (Mäntylä 2004: 28) points out that such classification "represents a continuum rather than discrete categories".

Cieslika (2015) stated that Yorio distinguishes between two types of conventionalized language: idioms and routine formulas (i.e. highly conventionalized fixed expression whose occurrence is tied to a standardized communication situation). These expressions are classified according to structural, syntactic and semantic criteria, but only the semantic classification will be discussed. From the semantic point of view, expressions can be transparent (i.e. formulaic expressions that are not idiomatic), such as your face looks familiar, semi-transparent (i.e. formulaic expressions or idioms that are somewhat metaphorical) such as to shake hands or skyscraper, and opaque (i.e. idioms or expressions whose meanings are not interpretable from their morphemes), such as to knock on wood. Yorio's categorizations is quite similar to Fernando's and Moon's, but he does not consider transparent expressions to be idioms at all, thus, with 
respect to the present study, this classification cannot be used.

One will be very tempted to settle for the surface meaning for example 'public school' one might think that public school is a governmental general school, despite this term is used for ' private schools in England'. To add, the idiom' bend someone's ear' may be considered as a form of punishment or threatening, whereas it means 'to talk to someone for a long'. Furthermore, 'war chest' may be taken as relating to heart but it means 'an accumulation of funds to finance a war effort', or ' a fund reserved for a particular purpose such as a political campaign'.

In opaque idioms every part of the idiom doesn't contribute to the whole meaning of the phrase. To consider for instance, the idiom (has \have cold feet) has no relation to coldness or feet, it rather means that he's scared. "The difference between semi-transparent and semi-opaque is intensively a subjective matter, but often the difference is remarkable by most people (Baker, 1992). The transparent and idiomatic readings are not simply remarked without a reference to the context.

\subsection{Idiomatic Translation}

Adelina and Dastjerdi (2011) showed that Idiomatic translation is a sort of translation which has the same meaning as the source language but is expressed in the natural form of the receptor language. Thus, when a translator gives priority to the typicality and naturalness of the TT, he may be forced in some cases, to drop, add or modify something in the source text (ST) to pick up the message across as atypical as possible to the TL. Translation student will work only 
into the language of which he has native knowledge. Native knowledge is defined as the ability to speak and write a language so fluently that the expression of thought is structurally, grammatically and idiomatically correct".

Idioms are not as frequent as in Arabic as in English. For the reason that, Classical Arabic has a wide range of vocabulary with highly specific meanings. Furthermore, it is very distinguished for its clarity and abundance of near synonyms. Whereas some languages have a single word to describe one thing, Arabic has hundreds for example, there are over 500 words for 'lion' 200 for' snake', each with a specific connotation (Ibn Faris, Fiqh al-Lugha, p.21). Such abundance in vocabulary gives words more flexibility to pick words without repetition, i.e. a word may have a particular collocation that is not shared with others.

It is very true that idioms are not easy to transfer from one language into another, due to its opaqueness accompanied with its metaphorical sense. Dickens (2002:147) states that "all lexicalized phrasal metaphors are idioms". By lexicalized metaphors, dickens et al et al refers to phrases whose meanings are metaphorically fixed and provided in dictionaries. For example, the word" rat" has two senses, firstly an animal, secondly a person who deserts his friends. The other sort of metaphors that fall outside idioms are such phrases that can be manipulated by readers (i.e. they have various readings with regard to how clever a person is in figuring out their meanings) and differ from contexts to others is. Those metaphors are considered non-lexicalized (Dickens, 2002). For example, 'a man is 
a tree' can be understood as ' he resembles trees in growing up; developing, bearing leaves and then when he gets old he becomes dry and loses his leaves. Consequently, many interpretations can be concluded based on the imagination of the reader.

While translating idioms one should bear in mind that if an equivalent idiom is figured out in the target language (TT), it should without doubt have the same connotations and all aspects of meanings related to the original idiom. But in case of failing to preserve such meanings in the TT, the metaphorical sense may be omitted.

\section{Previous Study}

\section{Badawi (2008)}

The study focused on the teachers' ability to translate culture-bound expressions and their translation strategy awareness. The study concluded that EFL prospective teachers' performance in translating culture-bound English expressions, is very poor. Badawi recommended that" teachers' should be provided with explicit training on translating culturebound aspects and expressions. EFL prospective teachers' should be provided with explicit training on positive translation strategies.

\section{Yuliasari (2011)}

The study analyzing whether or not the choice of the translation techniques affects the rendering of meaning, maintenance of humor, and acceptability of the translation. Consequently, a qualitative method was applied with content analysis technique and reader response analysis. Content analysis was used in comparing the source text (ST) and target text (TT) to 
find out the translation techniques used as a means of censorship and to find out the translators' reasons for choosing the techniques. Reader-response analysis was done to find out the readers' response to the rendering of meaning and maintenance of humor in the translation

\section{Glodjovic (2010)}

The research is about the problematic aspects of intercultural communication are considered in the context of cultural and linguistic barriers encountered in translation. She stated that culture is an obstacle in translation and mentioned Newmark definition of culture which is; the way of life and its manifestations that are peculiar to a community that uses a particular language as its means of expression, thus acknowledging that each language group has its own culturally specific features. Moreover, she mentioned the Newmark's methods to overcome the difference of cultures in translation. She also mentioned that translation according to Nida must make sense and convey the spirit and manner of the original, being sensitive to the style of the original, and should have the same effect upon the receiving audience as the original had on its audience.

\section{Shojaei (2012)}

This study tries to investigate and identify firstly some existing obstacles and problems in the process of translating inter-lingual idiomatic pairs, and then to suggest some theoretical strategies to overcome such difficulties. The study mentioned Mona Baker's (1992) classification of difficulties and strategies and the related subcategories mentioned, the study made an effort to analyze such classifications. Findings showed 
that there are a number of factors which should be considered in order to translate idiomatic expressions correctly. The most important of such factors include socio-linguistic elements, cultural aspects, linguistic and stylistic considerations as well as some specific metalingual factors. I

\section{Cook (2012)}

He confirmed in his study that Translation has an important role in the language sciences .Cook questions this neglect on many fronts, and argues convincingly for re-considering translation in language learning and teaching, claiming that the integration of translation in a teaching program is useful for most language learners.

\section{Zainudin and Awal (2011)}

They defined translation as an activity of mediating meaning from a source language into a target language. The ability to choose the correct translation technique is an indispensable skill to translators; therefore it is essential for a translation student to be aware of why a particular technique is used. It is mentioned in the study that, past literatures in translation studies have shown that although much has been written about the translation process and product, there is very little about the class dynamics in a translation classroom. Furthermore, they shed the light on translation training in class room they said "Translation training is about preparing students to become a mediator of language and culture, a computer expert, as well as the ability to market and promote one's language services."

\section{Calis \&Dikilitas (2012)}

This study analyzes elementary learners 'reaction to the use of translation as a L2 learning practice. A classroom-based research that lasted 7 weeks was 
conducted with 28 learners who were taught some grammatical subjects through the exercises based on translation as a L2 learning practice technique. Following this period, the participants were asked for their perceptions of this learning experience through a questionnaire .Results of the study show that learners, in general, have had positive ideas that support the use of translation as a practice. More specifically, they believe that use of translation helps them reading comprehension and memorize target vocabulary. They also report as their frequently used strategies that they use bilingual dictionaries and translate the text first and then try to understand it. The study concludes that translation tasks could promote learners' receptive skills and productive skills .

\section{Owji (2013)}

She stated that translation problems are; lexical problems (straight/denotative meaning, lexical meaning, metaphorical expression, semantic voids and proper names) and syntactic problems (including; word classes, grammatical relations, word order, style and pragmatic aspects). She mentioned the Chesterman's strategies i.e. syntactic strategy (literal translation, loan translation, transposition, unite shift, paraphrase structure change, clause structure change sentence structure change, cohesion structure change, level shift and scheme change), semantic strategy (synonymy, antonym, hyponymy, converses, trope change, abstraction change, distribution change, emphasis change, distribution change, paraphrase strategy) and pragmatic strategies (cultural filtering, explicitness change, information change, interpersonal change, speech act, visibility change, coherence change, partial change and trans-editing). 
She also specified baker's taxonomy which includes translation by more general word, translation by more neutral or less expressive word, translation by cultural substitution, translation by loan word, translation by paraphrasing using related words, translation by paraphrasing using unrelated words, translation by omission and translation by illustration

\section{Fernandez (2014)}

The study showed that, translation can be a great aid to foreign language learning. Ana B. Fernandez Guerra aimed at summarizing and assessing the arguments that encourage the use of translation in the foreign language classroom, supporting the integration of several forms of translating. Furthermore, the study presented the results of a survey that focused on students' perceptions and responses towards translation tasks and their effectiveness in foreign language acquisition. Results showed that students' attitudes were surprisingly positive for several reasons: translation is one of their preferred language learning tasks, it is motivating, it facilitates a deeper understanding of the form and content of the source language text, it increases learners' awareness of the differences between both linguistic systems, it allows them to re-express their thoughts faster and easier, and it helps them acquire linguistic and cultural knowledge.

\section{Results and discussion}

\section{1-EFL prospective Teachers' Ability to Translate idioms.}

Table 1: Participants Total Scores on idiomatic competence test.

\begin{tabular}{|l|c|r|}
\hline $\begin{array}{l}\text { Test Max Score } \\
\text { (Participants n43) X } \\
\text { (Items no 20) X (Item } \\
\text { Max. Score2). }\end{array}$ & $\begin{array}{r}\text { Required Score } \\
60 \text { of Max Score }\end{array}$ & $\begin{array}{r}\text { Obtained Score } \\
\text { Accurate+ Acceptable }\end{array}$ \\
\hline & 1720 & 538 \\
\hline
\end{tabular}


Table1 manifests that prospective teachers achieved scores on the idiomatic competence test (538), whereas the demanded cut off score is $(1032=60 \%)$. Such result reflects that prospective teachers, as a group found difficulty in translating idioms.

Table2: Participants' Mean Scores on the idiomatic competence test:

\begin{tabular}{|c|c|c|}
\hline Participants & Obtained Mean & Required Mean \\
\hline 43 & 12.51 & 24 \\
\hline
\end{tabular}

From table (2) it is very obvious that the achieved mean scores of the prospective teachers on the idiomatic competence test is (12.51), whereas the demanded cut-off score is (24). This consequence manifests that the participants were unable to fulfill the demanded mean scores. In conformity to this EFL prospective teachers, as a group failed to translate culture- based idioms.

Table 3: Participants' Total Results on the ICTT

\begin{tabular}{|c|c|c|c|}
\hline Participants & Fail & Pass & Total \\
\hline $\mathbf{N}$ & $\mathbf{3 7}$ & $\mathbf{6}$ & $\mathbf{4 3}$ \\
\hline$\%$ & $\mathbf{8 6 . 0 5 \%}$ & $\mathbf{1 3 . 9 5 \%}$ & $\mathbf{1 0 0 \%}$ \\
\hline
\end{tabular}

In order to make sure of the same outcome, table 2 indicates that $86.05 \%$ participants $(n=37)$ achieved a less score than the cut-off level of the idiomatic competence test ( 24 points $=60 \%$ ). Whereas most of the participants failed to pass the test, $13.95 \%$ of the participants $(n=6)$ only were able to pass the test, which in turn emphasizes that most of the EFL prospective teachers find difficulty in translating idioms.

Table 4: Participants' Detailed Results on the idiomatic competence test

\begin{tabular}{|c|c|c|}
\hline Criteria & $\mathrm{N}$ & $\%$ \\
\hline Fail= less than $60 \%$ & 37 & $86.05 \%$ \\
Fair=60\% to $69 \%$ & 3 & $6.97 \%$ \\
Good $=70 \%$ to $79 \%$ & 1 & 2.33 \\
Very good= $80 \%$ to $89 \%$ & 2 & 4.65 \\
\hline Excellent=90\% to $100 \%$ & 0 & 0 \\
\hline
\end{tabular}


To reassure the abovementioned, table 3 manifests that $86.05 \%$ of the participants $(n=37)$ got less scores than the level of the cut-off test which reveals that most of the participants failed to pass the idiomatic competence test.

Table: 5 Participants' Translation Performance on the idiomatic competence test

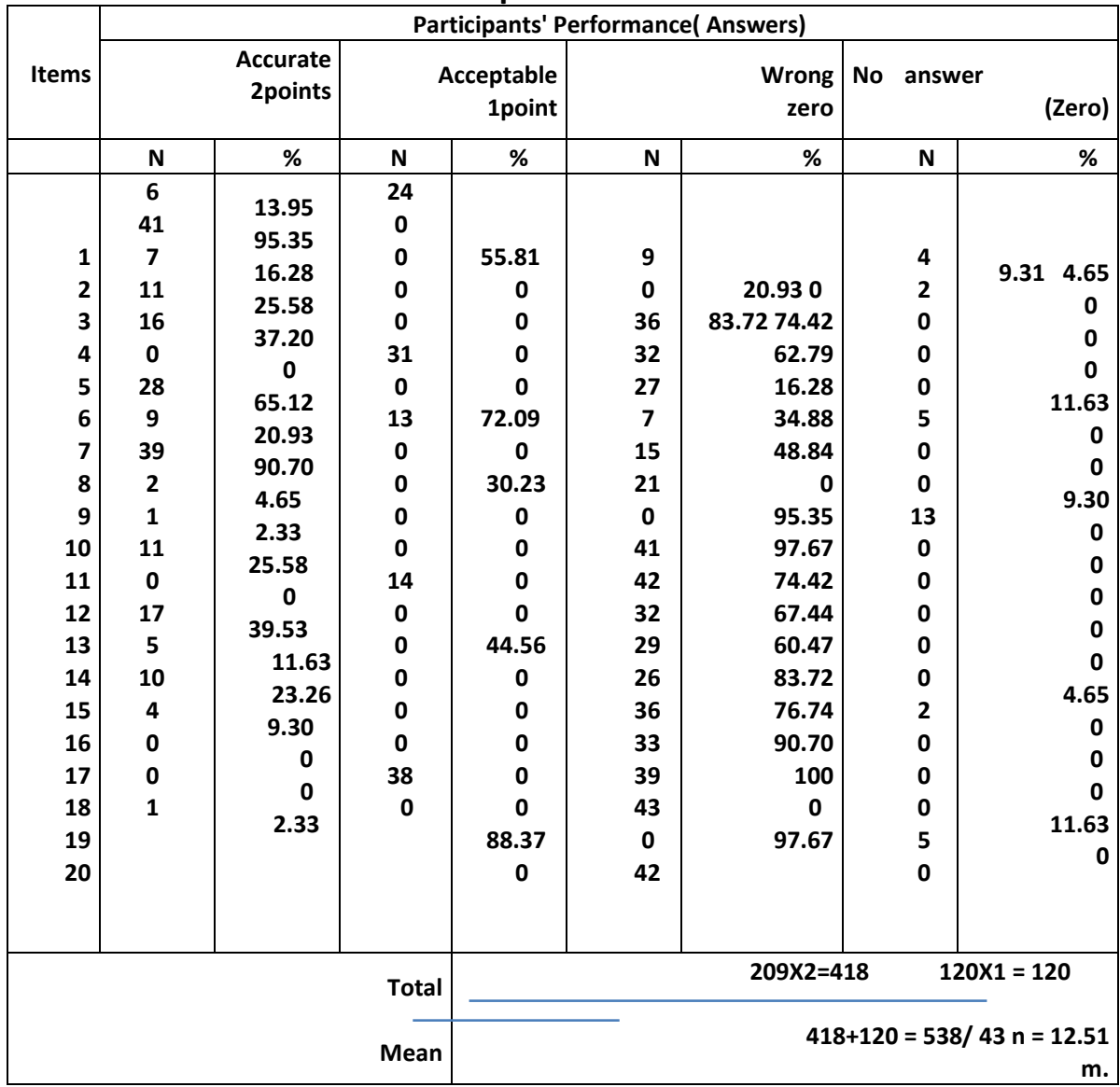

In conformity to this result, it is very clear that the participants were unable to translate idioms. Furthermore, the above table manifests that $6.97 \%$ of the participants $(n=3)$ obtained scores from $60 \%$ to $69 \%$, which in turn highlights the fact that the majority of the participants who were able to achieve the cut-off 
level of the idiomatic competence test failed to fulfill high scores and this also demonstrates their fragile ability to translate idioms. This output is further reassured by the result that $4.65 \%$ of the participants $(\mathrm{n}=2)$ obtained 'very good grade' $80 \%$ to $89 \%$. In spite of this no one of the participants was able to fulfill an excellent grade.

\section{Item (1)}

As a result of table 5 , it is very obvious that it demonstrates that $55.81 \% \quad(\mathrm{n}=24)$ participants managed to translate the target expression of the item 'tickled pink' of the first test into admissible translations:

\begin{tabular}{l|l|}
\hline Tickled pink & تغير وجهة \\
\hline $\begin{array}{l}13.95 \%(n=6) \text { of the participants could give exact } \\
\text { translations like for instance: }\end{array}$
\end{tabular}

Overall, $69.76 \%(n=30)$ of the participants were able to provide admissible and exact translations delivering the connotation of the expression 'tickled pink' which has the connotation of being shy. Such transition of meaning is rationally considered admissible since participants managed to benefit from the simple and obvious context where the expression came out. In conformity to this, they succeeded in guessing some culturally admissible meanings. To add, the pink color symbolizes the cultural connotative emotions of being shy as well as in Arabic language. Meanwhile, $20.93 \% \quad(n=9)$ of the participants mistranslated the same expression

كان وجه الفتاة منقط بالون الزهري

Also other participants could not translate the expression at all. It is totally clear that the inability of 
the participants to provide an accurate and admissible translation is due to literal translation and deficiency in cultural awareness.

\section{Test Item (2)}

As demonstrated above, the same table indicates that $95.35 \% \quad(n=41)$ of the participants produced admissible and exact translation to the target expression of the second test 'black and white'. This output reflects that the majority of the participants succeeded to provide admissible transitions like for example:

يري الاشياء بشكل محدد. كان و اضح

However, such transition may sound reasonable due to the fact that the target expression 'black and white' is common that's why the majority of the participants are fully aware of its cultural relevant meaning. 4.65\% $(n=2)$ of the participants meanwhile, failed to translate the target item. They might have known the exact meaning of the target expression however; they hesitate to use the same literal translation because it is transparent idiom which is used in Arabic and English culture.

\section{Test Item (3)}

In conformity to which introduced in the table 5 , $83.72 \%(n=36)$ of the participants were unable to produce sound and proper translations to the target expression of the third test 'in the red' such as:

$$
\text { لونها احمر - مكتوبة باللون الاحمر }
$$

$16.28 \%(n=7)$ only of the participants succeeded in providing proper and exact transitions to the expression hereby like:

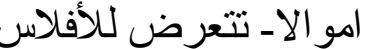


It is thought that the participants failed to produce accurate transitions to the target expression 'in the red' is due the fact that literal denotative meaning of the target expression is totally unlike its connotative cultural meaning. Hence, any attempt to guess the meaning or use literal translation misguided the majority of the participants.

\section{Test Item (4)}

With respect to the aforementioned in the table, only $25.58(n=11)$ of the participants could produce proper and exact transitions to the target expressions of the fourth test item 'out of the blue' like:

فجأة وبلا سابق انذار

On another level, 74.42\% (n=32) of the participants concluded incorrect translations such as:

خار ج اللون الازرق- ماعدا اللون الازرق

It is believed that the participants failed to translate the target expression in hand as a result for using the idiom 'out of the blue' which has no exact symbol in the Arabic language and culture. For that reasons the participants decided to use literal translation with the aim of indemnifying their fragile awareness of culture which is necessary for translating culture-bound expressions as well as idioms.

\section{Test Item (5)}

The table in addition, manifests that $62.79 \%(n=27)$ of the participants were unable to produce valid translations to the target expression of the fifth test item 'spill beans' as:

بسكب الفول

On the contrary, $37.20(\mathrm{n}=16)$ of the participants could provide accurate and acceptable translations to the same expression such as: 
يفشي الاسرار- يفضح الامر - يذيع الاخبار

It is very obvious that many of the participants attempt to use literal translation seeking for equivalence to this target expression. To add, the Arabic expression

\section{Test Item (6)}

This test item demonstrates that $72.09 \%(n=31)$ of the participants could produce proper and acceptable translations to the target expression of the 6th item 'chew the fat' as:

الغوص في سيرة الاخرين- التحدث عن الغير

On the contrary, $11.63 \%$ (n-5) of the participants provided incorrect translations such as:

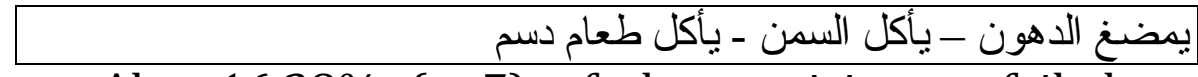

Also $16.28 \%(n=7)$ of the participants failed to translate the item.

\section{Test Item (7)}

It is clear that item 7 demonstrates that $65.12 \%$ $(n=280)$ of the participants could produce sound and exact translations to the target expression of the 7 th test item 'hot cake' such as:

Also other participants could not translate the expression at all. It is totally clear that the inability of the participants to provide an accurate and admissible translation is due to literal translation and deficiency in cultural awareness.

'hot cake"

ساخن مثل الكيك

As a matter of fact, that target expression is very current in the Arabic language for instance:

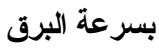


This reflects the meaning of speed or rapid. In spite of this, $34.88 \% \quad(n=15)$ of the participants found difficulty to benefit from such assimilation due to the fact that there is no attention paid to training on translation of collocations in erratic classes translation classes.

\section{Test Item (8)}

In this item it is obvious that $20.39 \%(n=9)$ of the participants introduced precise as well as proper translations to the target expression of the 8th test item 'kid gloves' as:

To handle with Kid gloves

يعامل بشكل جيد

However, $30.23 \%(n=13)$ of the participants gave admissible translation such as:

Meanwhile, 48.84\% (n=21) of the participants could not translate the same item correctly like for instance:

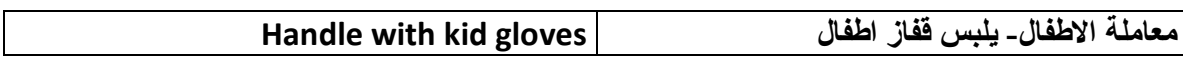

This was due to the fact that the participants were unable to give a correct translation to the expression since the term' hand gloves', this cultural connotation is not reflected in the Arabic culture.

\section{Test Item (9)}

This item displays that $90.70 \% \quad(n=39)$ of the participants made precise translation to the ninth test item target expression 'keep under your hat' as for example:

\section{Keep under your hat}

On the contrary, $9.305(\mathrm{n}=13)$ of the participants failed to translate the item hereby. They might find difficulty in translating the term 'under hat' properly due to the fact that literal translation can't transfer the cultural meaning of that expression. 


\section{Test Item (10)}

This item demonstrates that $95.35 \%(n=41)$ of the participants failed to introduce correct and precise translation to the tenth test item target expression 'pull through' like for example:

Pull through

Nevertheless, $4.65 \% \quad(n=2)$ of the participants introduced valid as well as precise translation such as:

\section{Test Item (11)}

In item 11 it is shown that $97.67 \%(n=42)$ of the participants could not provide valid translation to the seventh test item of the target expression 'isn't my cup of tea' such as:

\section{'isn't my cup of tea'}

ليست كاس شاى- كوب الشاى اتجليزلى- ليست كوب ماء.

Nevertheless, just one of the participants could provide a precise translation to the item like for example:

With regard to culture, the item in hand is considered one of the most complicated items included in the test due to the fact that the target expression 'my cup of tea' implies various culture indications in the American and Arabic cultures alike.

\section{Test Item (12)}

This item manifests that $74.427 \quad(n=32)$ of the participants failed to deliver valid translation to the target expression of the twelfth test item 'a red letter' such as:

In spite of this, $25.58 \%(\mathrm{n}=11)$ of the participants succeeded to provide precise translation to that expression such as: 


\section{Test Item (13)}

In this item it is very clear that $67.44 \%(n=29)$ of the participants were unable to provide proper translation to the target expression of the test item 'pull up his socks' such as:

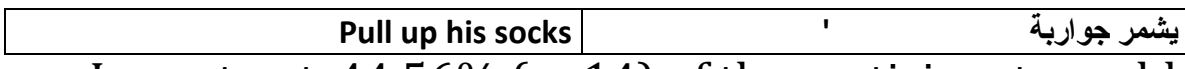

In contrast, $44.56 \%(\mathrm{n}=14)$ of the participants could introduce admissible translation like for instance:

\section{Pull up his socks}

يشمر ساعدية - يستعد

Accordingly, the majority of the participants found difficulty in translating this expression.

\section{Test Item (14)}

This item demonstrates that $60.47 \%(n-=26)$ of the participants failed to deliver a valid translation to the expression target of the fourteen test item 'apple of his eye' such as:

\begin{tabular}{|r|r|}
\hline Apple of his eye & مقلة عينة - يري تفاحة بعينة \\
\hline
\end{tabular}

Meanwhile, $39.53 \% \quad(n=17)$ of the participants succeeded to provide precise translation such as:

\section{\begin{tabular}{|r|r|}
\hline Apple of his eye & قرة عينة
\end{tabular}}

Actually, more than half of the participants were unable to give an accurate and valid translation to this expression. This arouses out of the lack of culture awareness in addition to resorting to literal translation which led at the end to in proper as well as inaccurate translation.

\section{Test item (15)}

This item indicates that $83.72 \%(n=36)$ of the participants found difficulty in introducing valid translation to the target expression of the fifteenth item 'at the death door' like for instance: 
Furthermore, 4.65\% (n=2) of the participants left the target item without translation. On the contrary, $11.63 \%(n=5)$ of the participants succeeded to provide precise translation such as:

\begin{tabular}{|r|r|}
\hline At the death door & على اعتاب الموت
\end{tabular}

Undoubtedly, the majority of the participants resorted to utilize literal translation that's why they failed to provide proper translation. In general, almost most of the participants failed to translate the expression.

\section{Test Item (16)}

This item demonstrates that $76.74 \%(n=33)$ of the participants were unable to introduce valid translation to the target expression of the sixteenth test item 'came down with cold' such as:

\begin{tabular}{|c|c|c|}
\hline \multicolumn{2}{|r|}{ 'come down with cold' } & \\
\hline
\end{tabular}

In contrast, $23.26 \% \quad(n=10)$ of the participants succeeded to provide precise as well as valid translation such as:

\begin{tabular}{|c|c|}
\hline 'come down with cold' & أصيب بالبرد \\
\hline
\end{tabular}

\section{Test item (17)}

This item highly manifests that $90.70 .74 \%(n=39)$ of the participants did not provide proper translation to the target expression in the seventeenth test item 'wear his heart in his sleeve' such as;

$9.30 \%(n=4)$ of the participants only were able to give precise translation to the expression hereby like for example:

\section{Wear his heart in his sleeve}

لا يكتم سرا- يخبر الجميع

Seemingly, the majority of the participants failed to provide correct translation which implies the culture 
reference of the term 'wear his heart in his sleeve '. This is because the word 'heart' indicates an emotional sense in the Arabic culture. The use of literal translation further led to in proper translations.

\section{Test item (18)}

This item indicates that $100 \% \quad(n=43)$ of the participants were unable to provide correct translation to the target expression of the eighteenth test term 'back on his feet' like for example:

\section{'back on his feet'}

ظهر قدمة_ التواء القدم- عكس السير.

Amazingly, the majority of the participants resorted to utilize literal translation seeking a translation for the target expression. Indeed, the participants' inability to provide a proper translation.

\section{Test item (19)}

This item displays that $88.37 \%(n=38)$ of the participants were unable to introduce sound translation to the target expression of nineteenth test item 'throw up' such as:

\begin{tabular}{|c|c|}
\hline 'throw up' & يرمي للأطلى - يقز عاليا. \\
\hline
\end{tabular}

Moreover, $11.63 \%(n=5)$ did not translate the item at all. Obviously, item 19 is regarded as one of the most complex items based on the fact that almost all the participants failed to provide proper translations to the item.

\section{Test item (20)}

This item manifests that $97.67 \%(n=42)$ of the participants failed to give valid translations to the target expression of the eighteenth test item 'at the drop of hat' like for example: في وقت سقوط القبعة .

Evidently, one participant only was able to provide a sound as well as precise translation to the target expression such as: 


\section{At the drop of hat}

في طرفة عين - في لمح البصر

Obviously, this term is further regarded as one of the most complicated terms due to the fact that one participant only succeeded to translate it properly. In addition, most of the participants resorted to use literal translation.

Ultimately, it is very obvious that outcomes in tables $1,2,3,4$ as well as 5 highlight the fact that most of the participants found difficulty in translating culturebound idioms due to what is above reflected through their performance in the awareness questionnaire on the translation strategy. This in fact promotes the initial hypothesis of the study. Moreover, this result is in conformity to Badawi (2008) and Cieslika (2015) who focused on the complexity of translating idioms.

\section{EFL Prospective Teachers' Translation Strategy Awareness}

Addition, Combination, Compensation, translation by paraphrase, Cultural equivalent, idiomatic translation, Descriptive equivalent, Functional equivalence, Adaptation, Paraphrase, Modulation, structure-shift, transposition, coherence change, speech act

Seemingly, the values which are mentioned in table 6 demonstrate that the overall score of the EFL Prospective Teachers concerning the awareness questionnaire of the translation strategy is (1298= 40.24\%) whereas the demanded score is (1612.5= $50 \%$ ). As a matter of fact the prospective of teachers failed to obtain the demanded cut-off score (1612.5) of the TSAQ. This in turn manifests the EFL prospective teachers' lack of translation strategy awareness while translating culture-bound idioms. This was deeply indicated through their answers regarding the TSAQ. 
On the other hand, item 7, 9, and 14 surpassed the cutoff level (Item Acceptable Value= 107.5) since they obtained 124, 180 and 189 respectively. Actually, this outcome reveals a number of negative references since they have nothing to do with introducing the accurate or natural meaning. Moreover, the 'literal translation' as well as the 'Guessing' strategies are not regarded as positive in case of translating idioms in which such strategies cannot meet the needs of transferring the culture load which is implied in the target cultural idioms accurately.

Table 6: Participants' Strategy Awareness

\begin{tabular}{|c|c|c|}
\hline No & (Strategies) & $\begin{array}{l}\text { Total Response Value= Strategy frequency } X \\
\text { Response Value } \\
\text { Item Max. Total Response Value }=\mathbf{2 1 5 ( 1 0 0 \% )} \\
\text { Item Acceptable Value }=107.5(50 \%) \\
\sum \quad \text { Item Max. Total Response Value }=\mathbf{3 2 2 5}(\mathbf{1 0 0 \% )} \\
\sum \quad \text { Item Min. Total Response Value }=1612.5(50 \%)\end{array}$ \\
\hline 1 & Addition & 86 \\
\hline 2 & Combination & 46 \\
\hline 3 & Compensation & 86 \\
\hline 4 & translation by paraphrase & 45 \\
\hline 5 & Cultural equivalent & 54 \\
\hline 6 & idiomatic translation & 49 \\
\hline 7 & Descriptive equivalent & 128 \\
\hline 8 & Functional equivalent & 57 \\
\hline 9 & Adaptation & 180 \\
\hline 10 & Paraphrase & 61 \\
\hline 11 & Modulation & 64 \\
\hline 12 & structure-shift & 72 \\
\hline 13 & transposition & 83 \\
\hline 14 & coherence change & 189 \\
\hline 15 & speech act & 98 \\
\hline Total & & 1298 out of 3225 \\
\hline
\end{tabular}

Total = Item Max. Total Response Value (215) X n. items (15) = Max.3225 


\section{Conclusion}

With respect to the results of the study, it is concluded that the performance of the EFL prospective teachers in translating idioms of English is so weak according to their scores obtained regarding the idiomatic competence test. To add, the strategy awareness of the EFL prospective teachers is as weak as indicated via the repetition of their answers within the TSAQ (The translation strategy awareness questionnaire). Most of the EFL prospective teachers further tend to use the strategies of literal translation as well as guessing.

\section{Recommendations}

As a matter of great concern, EFL prospective teachers have to obtain a clear training concerning the cultural translation such as; idioms. They have further to be supported with an obvious training concerning the positive strategies of translation. Culture-bound idioms should put into consideration during practices in translation classes. Moreover, there should be a focus on culture-based idioms during translation courses. Students should be aware of the role of idiomatic translation. On another deeper level, there should be a revival to error as well as comparative analysis within the field of translation. There should further be an explicit training program with the aim of getting the faculty members acquainted with the translation of culture aspects in conformity to the ongoing status of teaching translation at the university level. Likewise, it is highly recommended that a training program be suggested for the purpose of making students aware of translation strategies. Furthermore, a research should be done in order to examine the capacity of students to translate literary texts for the reason that idioms is considered as an inseparable element of culture. 


\section{References}

Adelina, A. \& Dastjerdi, V. (2011). Translation of idioms a hard task for translator.

- Al- Shaw, M. \& Mahadi, T. (2012). Strategies for Translating Idioms from Arabic into English and Vice Versa.

- Aly, A. (2002). Translation strategies of EFL student teachers: a think a loud protocol-based case study, ERIC, ED4903.

- Anica, G. (2010). Translation as a Means of Cross-cultural Communication: Some Problems in Literary Text Translations.

- Awal\& Norsimah (2011) Translation Techniques: Problems and Solutions.

- Badawi, M. (2008). Investigating EFL prospective teachers' ability to translate culture bound expressions. Retrieved from, https://files.eric.ed.gov/fulltext/ED503396.pdf

- Balfaqeeh, N. (2009). Strategies for translating idioms and culturally-bound expressions within the human development genre, open distance learning MA TEFL/TESL/applied linguistics/ translation studies. The University of Birmingham

Calis, E. \& Dikilitas, K. (2012). The use of translation in EFL classes as $\mathrm{L} 2$ learning practice.

- Carrere, A. (2006). Translation and language teaching.

- Cheng, S. (2017) .Translation Competence Development among Learners :A Problem-Solving Perspective.

- Cieslika, A. (2015). Idiom acquisition and processing foreign language learners.

- Cook, G. (2010). Translation in language teaching. Derived from: https//doi.org/10.1093/applin/ams005.

- Cook, G. (2012) .Translation in Language Teaching.

- Dabaghi, A. \& Pishbin, E. \& Niknasab, L. (2010). Proverbs from the Viewpoint of Translation.

- Dickens, J. (2004).Thinking Arabic Translation, A Course in Translation Method: Arabic to English.

- Duff, A. (1998). Translation. Oxford university press, Oxford.

- Eda, C. \&Kenan, D. (2012). The use of translation in EFL classes as L2 learning practice.

- Elewa, A. (2016). Levels of Translation. Cairo, Egypt: Albayan.

- Geeraert, K. (2015). As a clear day: the transparency of English Idiomatic expressions.

- Gaber, M. (2002): teaching translation in Egyptian national universities. Translation journal, vol.6 no.1. Retrieved from, http:// accurapid.com/journal/19edu.htm).

- Glodjovic, A. (2010). Translation as a means of cross cultural communication: some problems in literary text translation. 
Retrieved from: http://facta.junis.ni.ac.rs/lal/lal201002/lal20100205.pdf.

- Goundareva, I. (2011). Effect of translation practice on vocabulary acquisition.

- Guerra, A. (2012). Translating culture problem strategies and practical strategies.

- Guerra, F. (2014) the usefulness of Translation in Foreign Language Learning: Students' Attitudes.

- Kavaliauskiene, G. \& Kaminskiene, L. (2007). Translation as a learning tool in English for specific purpose.

- Mantyla, K. (2004) .Idioms and language users: the effect of characteristics of idioms on their recognition and interpretation by native and nonnative speakers.

- Marin, P. \& Clavijo, B. (2013). Identifying Translation Teaching Strategies.

- Nattinger, J \& Decarrio, J. (1992). Lexical phrase and language teaching. Oxford university press. Oxford.

- Owji, Z. (2013) .Translation strategies. Translation Journal, Volume 17, No. 1.

- Pan, L. (2012) .Stance Mediation in News Translation: A Case Study of Sensitive Discourse on China 2008. PhD Thesis University of Macau.

- Plonska, p. (2014). Strategies of Translation: "psychology of language and communication.

- Poshi. I. \& Lacka, F. (2016). Strategies in translation idioms and fixed expressions from English to Albanian.

- Pym, A. (2013) .translation and language learning: the role of translation in teaching languages in European Union. Derived from: http:/www.researchgate.net/publication/258940012.

- Shojaei, A. (2012). Translation of Idioms and Fixed Expressions: Strategies and Difficulties.

- Sinclair, J. (1991) .Corpus, concordance and collocation. Oxford University press. Oxford.

- Teilanyo (2007). Figurative Language in Translation: A Study of J.P. Clark's The Ozidi Saga. Retrieved from: https://www.erudit.org/en/journals/meta/2007-v52-n2meta1727/016073ar/.

Yousefi, S. (2017). Translation of cultural specific items. Journal of applied linguistics and language research, volume 4, issue 5, 2017. Pp.62-75.retrieved from: www.jallr.com.

Yuliasari, I. (2011). Translator censorship in English Indonesian translation of Donald Duck comics. 